\title{
Electronic properties of ion-implanted yttria-stabilized zirconia
}

\author{
U. Vohrer, H.-D. Wiemhöfer ${ }^{1}$, W. Göpel \\ Institute of Physical and Theoretical Chemistry of the University of Tübingen, Auf der Morgenstelle 8, D-7400 Tübingen, Germany
}

\author{
B.A. van Hassel and A.J. Burggraaf \\ Department of Chemical Technology, Laboratory for Inorganic Chemistry, Materials Science and Catalysis, University of Twente, \\ P.O. Box 217, NL-7500 EA Enschede, The Netherlands
}

Received 1 May 1992; accepted for publication 22 October 1992

\begin{abstract}
Ion implantation of iron and titanium has been applied to modify the surface properties of polycrystalline yttria-stabilized zirconia $\left(\left(\mathrm{ZrO}_{2}\right)_{0.87}\left(\mathrm{YO}_{1.5}\right)_{0.13}=(\mathrm{YSZ})\right)$ discs in an attempt to prepare surfaces with a mixed conductivity and by this an enhanced surface oxygen exchange kinetics. Surface-sensitive spectroscopic techniques were applied to investigate the implanted layers as a function of different pretreatments such as oxidation, reduction and annealing. Depth profiles were recorded by Rutherford Backscattering Spectroscopy (RBS) and X-ray Photoelectron Spectroscopy (XPS) in combination with sputtering. Ion Scattering Spectroscopy (ISS) and XPS were used to investigate the surface composition and valency of implanted ions. Electronic properties like the band gap, the work function and the energy difference between the Fermi level and valence band edge $\left(E_{\mathrm{F}}-E_{\mathrm{V}}\right)$ were obtained from Ultraviolet Photoelectron Spectroscopy (UPS) and Electron Energy Loss Spectroscopy (EELS). Overlayers of $\mathrm{Fe}_{2} \mathrm{O}_{3}$ or $\mathrm{TiO}_{2}$ are formed during oxidation of as-implanted samples. The $\mathrm{Fe}$ - and Ti-oxides could be reduced in hydrogen to the oxidation states $\mathrm{Fe}^{2+}, \mathrm{Fe}^{0}$ or $\mathrm{Ti}^{3+}$. Annealing of the samples leads to decreased surface concentrations of the implanted ions due to in-diffusion. At the surface of the annealed iron-implanted samples, $\mathrm{Fe}^{2+}$ and metallic Fe could be generated after further reduction whereas at the surface of the annealed $\mathrm{Ti}$-implanted samples only $\mathrm{Ti}^{4+}$ was detectable.
\end{abstract}

\section{Introduction}

Fast electrode reactions of oxygen and of other gases are of primary importance for high temperature fuel cells, oxygen pumps, and oxygen sensors based upon yttria-stabilized zirconia (YSZ) as solid electrolyte $[1,2]$.

The oxygen reduction, in particular, is described by the following overall electrode reaction:

$$
\mathrm{O}_{2}(\mathrm{~g})+2 \mathrm{~V}_{\mathrm{o}}+4 \mathrm{e}^{-} \rightleftharpoons 2 \mathrm{O} \times
$$

where according to Kröger-Vink notation, $\mathrm{O}_{\mathrm{O}}^{\times}$is a normal $\mathrm{O}^{2-}$ ion in the yttria-stabilized zirconia lattice and $\mathrm{V}_{\mathrm{O}}^{*}$ is a doubly charged oxygen vacancy. For noble metal electrodes like platinum the exchange reaction is geometrically limited to the three phase line between the solid electrolyte, metal electrode and

\footnotetext{
1 To whom correspondence should be addressed.
}

gas atmosphere. Besides properties of the metal surface, the surface of the solid electrolyte, too, is known to have a pronounced influence on the rate of this oxygen exchange reaction at temperatures below $700^{\circ} \mathrm{C}$ [3-5]. It may provide active sites for oxygen adsorption along which adsorbed oxygen species are transported to the noble metal electrode, but the electrolyte surface itself does not participate in the electron transfer reaction as its electronic conductivity is too low. If electronic conductivity besides the high oxygen ion conductivity could be provided over the entire electrolyte surface, the reaction of oxygen, electrons and oxide ions would no longer be solely limited to the three-phase line. We therefore expect a significant increase in oxygen exchange kinetics under these conditions.

A possible solution is the use of mixed conducting oxides, with a high ionic and electronic conductivity $[4,6,7]$. Another solution is the modification of the 
solid electrolyte surface itself. Recent experiments have shown, that ion implantation in particular is a powerful technique to modify the surfaces of ceramic electrolytes [8-11]. Four-point probe conductivity measurements on Ti-implanted yttria-stabilized zirconia thin films ( $53 \mathrm{~nm}$ thick), showed an increase of the total conductivity by a factor $100-$ 1000 after reduction in $\mathrm{H}_{2}\left(P_{\mathrm{H}_{2}}=1 \mathrm{~atm}, 800^{\circ} \mathrm{C}\right)$ [12]. This is due to the formation of an overlayer of nonstoichiometric $\mathrm{TiO}_{2-x}$, as shown in this paper, which is an $n$-type semiconductor [13]. After implantation of iron, the equilibrium oxygen exchange current density at the electrode $\mathrm{Au}, \mathrm{O}_{2}(\mathrm{~g}) / \mathrm{yttria}$ stabilized zirconia increased by a factor 10-50. Furthermore the apparent double layer capacitance of the $\mathrm{Au}, \mathrm{O}_{2}(\mathrm{~g}) / \mathrm{Fe}$ implanted $\mathrm{YSZ}$ interface proved to be a factor 10-100 higher in comparison with the non-implanted interface [14].

In this paper we present experimental results obtained with surface analytical techniques, in particular with XPS, UPS and EELS as well as ISS and RBS which give the distribution of implanted ions and clarify the electronic properties of the ion-implanted solid electrolyte surface [15-20].

We show the properties of zirconia surfaces implanted with iron and titanium and their differences as well as the effect of different treatments on surface composition and the electronic structure of YSZ.

\section{Experimental}

The preparation of the yttria-stabilized zirconia $\left(\left(\mathrm{ZrO}_{2}\right)_{0.87}\left(\mathrm{YO}_{1.5}\right)_{0.13} \ldots \mathrm{YSZ}\right)$ discs as well as the ion implantation have been described elsewhere $[9,20]$. In this paper, experiments were performed on YSZ-discs, implanted with $15 \mathrm{keV}{ }^{56} \mathrm{Fe}$ (YSZ $(\mathrm{Fe})$ ) or ${ }^{48} \mathrm{Ti}(\mathrm{YSZ}(\mathrm{Ti})$ ) up to a dose of $8 \times 10^{16} \mathrm{at} \cdot \mathrm{cm}^{-2}$. Oxidation of the samples was performed at $400^{\circ} \mathrm{C}$ for $15 \mathrm{~min}$ in 1 bar $\mathrm{O}_{2}$ ("oxidized sample"), whereas reduction was carried out at $800^{\circ} \mathrm{C}$ for $15 \mathrm{~min}$ in 1 bar $\mathrm{H}_{2}$ ("reduced sample"). To obtain a decrease of the surface concentration of the implanted ions due to in-diffusion the samples were annealed at $1000^{\circ} \mathrm{C}$ for three hours in a separate furnace ("low-concentration-sample").

Rutherford backscattering (RBS) experiments have been performed with the $5 \mathrm{MeV}$ Van der Graaf accelerator of the LAN of the State University of Groningen and X-ray photoelectron spectroscopy (XPS) depth profiles have been determined with the Kratos X SAM-800 apparatus of the Centre for Materials Science (CMO) at the University of Twente. More details about these methods can be found in ref. [20].

Surface preparations like oxidation-treatments $\left(800^{\circ} \mathrm{C}, 1\right.$ bar $\left.\mathrm{O}_{2}\right)$, reduction-treatments $\left(800^{\circ} \mathrm{C}, 1\right.$ bar $\mathrm{H}_{2}$ ), or sputtering $\left(\mathrm{Ar}^{+}\right)$together with surface spectroscopic techniques have been performed in a combined ultrahigh vacuum (UHV) system at the University of Tübingen [21]. Ion scattering spectroscopy (ISS) was carried out with an ion-source (IQE $12 / 38$, Leybold) using $1 \mathrm{keV}^{4} \mathrm{He}^{+}$as primary ions, X-ray photoelectron spectroscopy (XPS) with an X-ray source $(\mathrm{Mg} \mathrm{Ka} 1253.6 \mathrm{eV}, \mathrm{Al} \mathrm{Ka} 1486.6$ $\mathrm{eV}$, VSW), Ultraviolet photoelectron spectroscopy (UPS) with an UV-source (He-gas discharge UVS, Leybold He I $21.21 \mathrm{eV}$, He II $40.8 \mathrm{eV}$ ) as well as electron energy loss spectroscopy (EELS) with an electron gun (EQ 22/35, Leybold) using $300 \mathrm{eV} \mathrm{e}^{-}$. The energy analyzer (HA 150, VSW) was located perpendicular to the sample surface.

\section{Results and discussion}

\subsection{Surface composition}

Ion scattering spectroscopy (ISS) probes the first atomic layer of a solid surface. This technique was used to monitor the changes in surface composition of the ion-implanted zirconia surfaces after different succeeding treatments. Fig. 1 shows ISS spectra for an (a) as-implanted-, (b) oxidized- and (c) the "low-concentration"-YSZ(Fe)-sample.

The spectrum of the as-implanted sample shows the expected result: the outermost surface layer mainly consists of iron, oxygen and yttrium/zirconium. Signals for yttrium and zirconium appear at the same energy in the ISS spectrum. After oxidation of the as-implanted sample at $800^{\circ} \mathrm{C}\left(1 \mathrm{bar} \mathrm{O}_{2}\right.$ for $15 \mathrm{~min}$ ) the surface is mainly composed of $\mathrm{O}$ and $\mathrm{Fe}$ with almost no $\mathrm{Y}$ and $\mathrm{Zr}$ (fig. $1 \mathrm{~b}$ ). This is explained by the formation of an $\mathrm{Fe}_{2} \mathrm{O}_{3}$ overlayer. In this study we are interested in the electronic properties of $\mathrm{Fe}$ doped YSZ. In order to prevent the $\mathrm{Fe}_{2} \mathrm{O}_{3}$ overlayer 


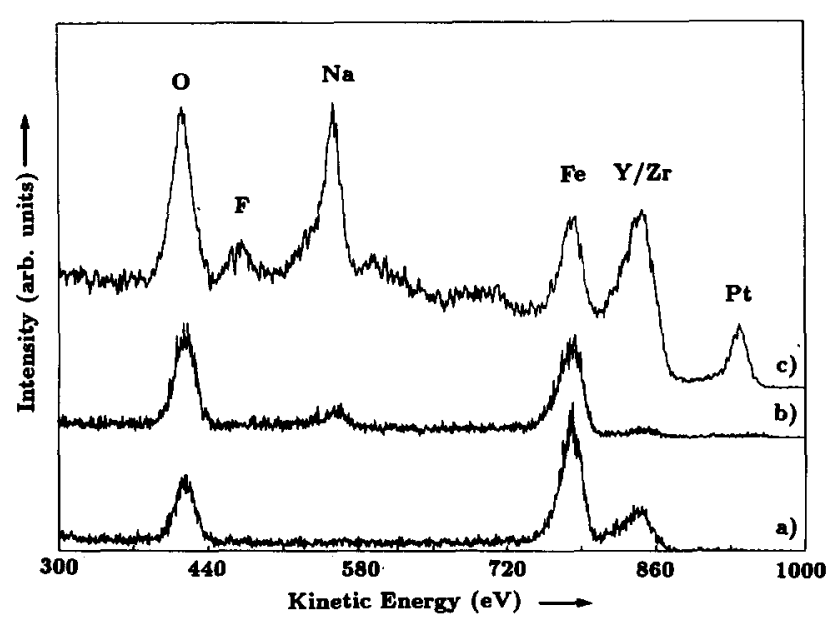

Fig. 1. Low energy ion scattering spectra $\left(1 \mathrm{keV} \mathrm{He}{ }^{+}\right)$of YSZ after implanting $15 \mathrm{keV} \mathrm{Fe}$ ions up to a dose of $8 \times 10^{16} \mathrm{at} \cdot \mathrm{cm}^{-2}$ : (a) as-implanted state; recorded at ambient temperature; (b) after oxidation at $400^{\circ} \mathrm{C}, P_{\mathrm{O}_{2}}=1 \mathrm{bar}, 15 \mathrm{~min}$; recorded at $700^{\circ} \mathrm{C}$; (d) after annealing the sample in air for three hours at $1000^{\circ} \mathrm{C}$; recorded at $700^{\circ} \mathrm{C}$.

from influencing the measurements, the sample was annealed at $1000^{\circ} \mathrm{C}$ for three hours. This annealing decreases the Fe cation fraction at the surface from 0.55 to 0.15 , as calculated from experimentally determined diffusion coefficients [20]. The resulting cation fraction of 0.15 is equal to the equilibrium solid solubility of $\mathrm{Fe}_{2} \mathrm{O}_{3}$ in $\mathrm{YSZ}$ at $1500^{\circ} \mathrm{C}$ in air [10]. In fig. 1c the ISS-spectrum of such an annealed YSZ (Fe)-sample is depicted. The decrease of the Fepeak (and therefore of the Fe-concentration) in comparison to the $(\mathrm{Y} / \mathrm{Zr})$-peak is clearly observed. Evaporation of $\mathrm{Fe}$ from the surface is negligible as deduced previously from results of depth profile analysis by means of RBS [20]. Surface segregation of $\mathrm{Na}$, however, was detected after annealing as observed on non-implanted YSZ, too [17]. A small Pt peak in fig. 1c is due to the sample holder.

Analogous results as described above for the $\mathrm{Fe}$ implanted samples have been obtained for the Tiimplanted samples: i.e. formation of a $\mathrm{TiO}_{2}$ overlayer after oxidation of the as-implanted samples and formation of a nonstoichiometric $\mathrm{TiO}_{2-x}$ overlayer after reduction.

\subsection{Depth profiles}

Depth profiles were recorded to investigate the cation fraction of the implanted ions after several treatments. Fig. 2 shows the depth profiles of Fe and $\mathrm{Ti}$ in $\mathrm{YSZ}(\mathrm{Fe})$ and YSZ(Ti) after oxidation at $400^{\circ} \mathrm{C}$ for $30 \mathrm{~min}$ in air, as determined by RBS ( (O) $\mathrm{Fe} ;(\Delta) \mathrm{Ti})$ ) and XPS in combination with sput-
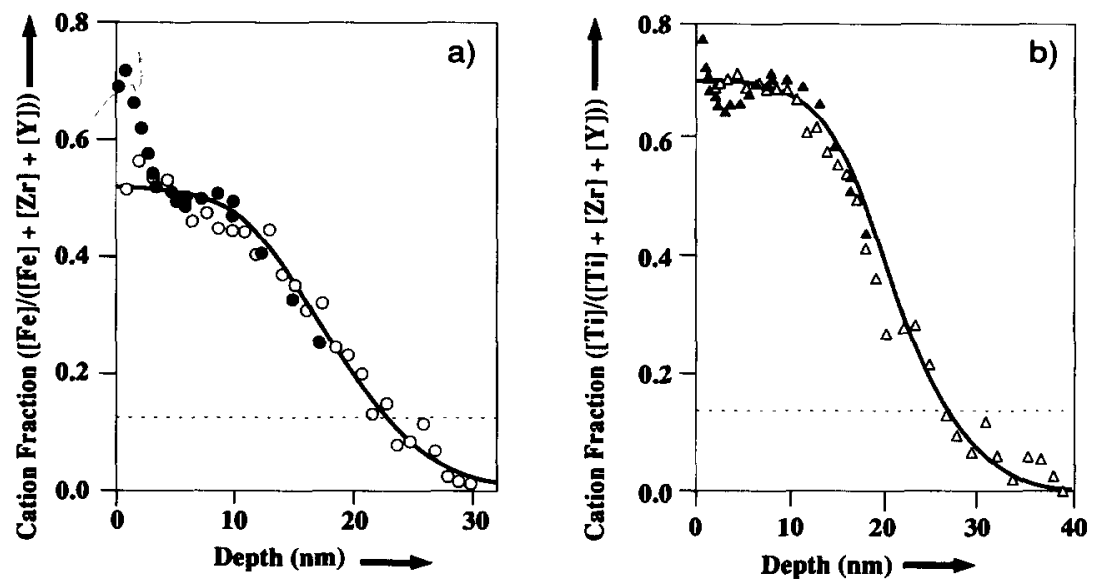

Fig. 2. (a) Cation fraction of Fe versus depth curve of YSZ after implanting $15 \mathrm{keV}$ Fe ions up to a dose of $8 \times 10^{16}$ at.cm ${ }^{-2}$ and subsequent oxidation at $400^{\circ} \mathrm{C}$ in air during $30 \mathrm{~min}$ : (O) determined by RBS; (O) determined by XPS in combination with sputtering. (b) Cation fraction of Ti versus depth curve of YSZ after implanting $15 \mathrm{keV} \mathrm{Ti}$ ions up to a dose of $8 \times 10^{16}$ at $\mathrm{cm}^{-1}$ and subsequent oxidation at $400^{\circ} \mathrm{C}$ in air during $30 \mathrm{~min}:(\Delta)$ determined by RBS; $(\Delta)$ determined by XPS in combination with sputtering. The horizontal broken line represents the equilibrium solid solubility level of $\mathrm{Fe}_{2} \mathrm{O}_{3}$ or $\mathrm{TiO}_{2}$ in $\mathrm{YSZ}$ at $1500^{\circ} \mathrm{C}$. The equilibrium solid solubility of 7 mol\% $\mathrm{Fe}_{2} \mathrm{O}_{3}$ corresponds to a cation fraction of 0.15 . 
tering ( ( $)$ Fe; ( $\Delta$ ) $\mathrm{Ti})$ ). XPS was more useful to determine the $\mathrm{Fe}$ or $\mathrm{Ti}$ concentration in the first 5 $\mathrm{nm}$ of the YSZ sample.

A remarkable difference exists between the maximum cation fraction of the $\mathrm{Fe}$ and $\mathrm{Ti}$ depth profiles ( 0.50 and 0.70 respectively). The Fe depth profile (fig. 2a) shows a strong enrichment of $\mathrm{Fe}$ at the outermost surface layer extending over $3 \mathrm{~nm}$. A similar result is obtained for Ti-implanted YSZ (fig. 2b). Below this Ti-rich layer, however, a maximum appears in the Ti depth profile at $8 \mathrm{~nm}$. The horizontal line at $15 \mathrm{cat} \%$ in fig. 2 represents the $\mathrm{Fe}$ and $\mathrm{Ti}$ concentration which corresponds to the equilibrium solid solubility of $\mathrm{Fe}_{2} \mathrm{O}_{3}[10]$ and $\mathrm{TiO}_{2}$ [19] respectively in YSZ at $1500^{\circ} \mathrm{C}$ in air. The total surface concentration of $\mathrm{Fe}$ and $\mathrm{Ti}$ atoms implanted in the samples, as obtained by integrating the depth profile is $3 \times 10^{16}$ and $3.5 \times 10^{16} \mathrm{at} \cdot \mathrm{cm}^{-2}$, respectively.

\subsection{Oxidation states of implanted atoms}

XPS was also used to study the oxidation state of Fe and Ti ions in as-implanted YSZ samples as well as after different treatments (oxidation, reduction and annealing as described above). Special interest concerns the oxidation state after annealing (i.e. after lowering of the surface concentration of implanted ions) and a subsequent reduction. If the implanted ions occur in two different oxidation states, i.e. $\mathrm{Fe}^{2+} /$ $\mathrm{Fe}^{3+}$ or $\mathrm{Te}^{3+} / \mathrm{Ti}^{4+}$, electron hopping between $\mathrm{Fe}$ - or $\mathrm{Ti}$-ions becomes probable at high enough $\mathrm{Fe}$ or $\mathrm{Ti}$ concentrations thus leading to electronic conductivity [22].

Implantation of Fe or Ti in YSZ without any further treatment results in a nonstoichiometric oxygen deficient and non-equilibrium surface layer in which different oxidation states of $\mathrm{Fe}$ are found such as metallic $\mathrm{Fe}^{0}, \mathrm{Fe}^{2+}$ and $\mathrm{Fe}^{3+}$ and, in case of Ti-implanted samples, $\mathrm{Ti}^{4+}, \mathrm{Ti}^{3+}$, and $\mathrm{Ti}^{2+}$ [15]. After oxidation in air at $400^{\circ} \mathrm{C}$, the ideal stoichiometry of the samples is restored and the implanted cations are present in their highest oxidation state $\left(\mathrm{Fe}^{3+}\right.$ and $\mathrm{Ti}^{4+}$ ). This result is for $\mathrm{Fe}$ in accordance with measurements performed with Conversion Electron Mössbauer Spectroscopy (CEMS) [32].

Fig. 3 summarizes XPS-spectra for $\mathrm{Fe}\left(2 \mathrm{p}_{3 / 2,1 / 2}\right)$ of an as-implanted $\mathrm{YSZ}(\mathrm{Fe})$-sample after a preparation cycle consisting of (a) oxidation, (b) subse-

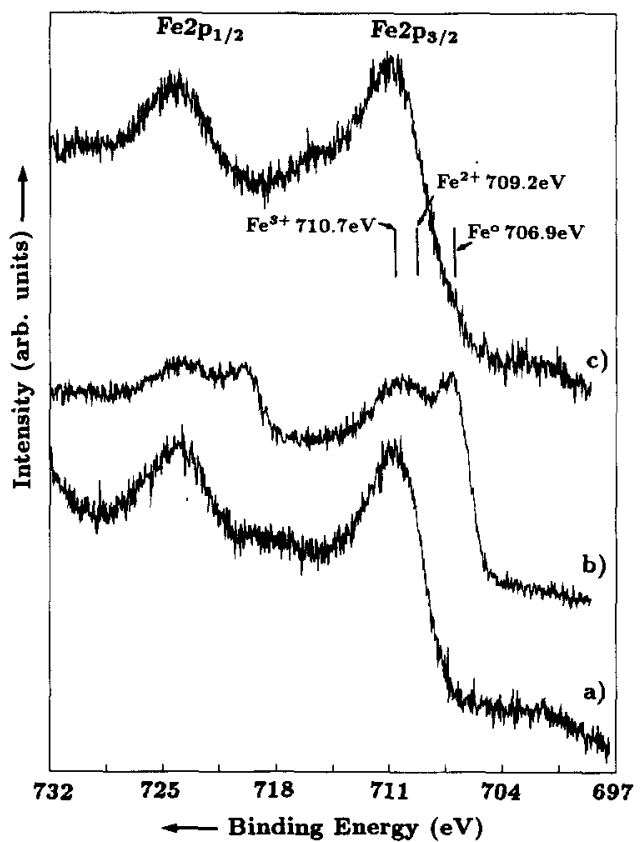

Fig. 3. XPS spectra for $\mathrm{Fe}\left(2 \mathrm{p}_{3 / 2,1 / 2}\right):(\mathrm{a})$ after oxidation at $800^{\circ} \mathrm{C}$ in air (separate furnace); (b) after reduction at $800^{\circ} \mathrm{C} P_{\mathrm{H}_{2}}=1$ bar, $15 \mathrm{~min}$; (c) after a subsequent exposure to a dose of $1000 \mathrm{~L}$ oxygen.

quent reduction followed by (c) an adsorption of $1000 \mathrm{~L}$ oxygen. The spectrum of the oxidized sample shows peaks at binding energies of $710.7 \mathrm{eV}$ and 724 $\mathrm{eV}$ corresponding to $\mathrm{Fe}^{3+}$. After reduction (fig. 3b) the peaks at 706.9 and $720 \mathrm{eV}$ clearly indicate metallic $\mathrm{Fe}^{0}$. The additional broad peak at 709.2 and $721 \mathrm{eV}$ is attributed to $\mathrm{Fe}^{2+}[23,26]$. A small exposure to oxygen of $1000 \mathrm{~L}$, however, was sufficient to reoxidize all $\mathrm{Fe}$ at the surface to $\mathrm{Fe}^{3+}$ (see fig. 3c). It can be concluded, that reduced $\mathrm{Fe}^{2+}$ at the surface is only stable under very low oxygen partial pressures.

According to our results from ISS (see section 3.1) the surface consists mainly of iron oxide. Pure $\mathrm{Fe}_{2} \mathrm{O}_{3}$ is an $n$-type semiconductor below $800^{\circ} \mathrm{C}$ and its conductivity is determined by electronic charge carriers [25]. If an intact $\mathrm{Fe}_{2} \mathrm{O}_{3}$-surface film is present, it may also induce an electronic conductivity at the surface of the stabilized zirconia.

To analyze the surface composition and the oxidation state of samples with concentrations of the implanted ions below the solubility-level, an annealing was carried out as described in Section 2. 
These samples were then subjected to oxidation, reduction and oxygen adsorption treatments just like the as-implanted pellets. The spectra obtained from samples with high or low concentrations of the implanted ions showed no large differences. It can be concluded, however, that implanted iron can be reduced to $\mathrm{Fe}^{2+}$ and $\mathrm{Fe}^{0}$, if the concentration is below the solubility level. Therefore, an electron-hopping may be possible due to the simultaneous presence of different oxidation states of iron. An increase of the electronic conductivity has been discussed for instance in $[10,24]$ for $\mathrm{Fe}_{2} \mathrm{O}_{3}$ doped $\mathrm{YSZ}$ at temperatures below $500^{\circ} \mathrm{C}$.

Analogous measurements were performed on titanium implanted samples. The spectrum of the asimplanted, oxidized sample shows peaks at binding energies of $458.5 \mathrm{eV}\left(\mathrm{Ti}_{2} \mathrm{p}_{3 / 2}\right)$ and $464.2 \mathrm{eV}$ ( $\mathrm{Ti} 2 \mathrm{p}_{1 / 2}$ ) corresponding to $\mathrm{Ti}^{4+}$. After reduction of this sample, a significant amount of $\mathrm{Ti}^{3+}\left(\mathrm{Ti}_{2} \mathrm{p}_{3 / 2}\right.$ $457 \mathrm{eV}$; Ti2 $\mathrm{p}_{1 / 2} 463 \mathrm{eV}$ ) is present at the surface as depicted in fig. 4. A complete reoxidation to $\mathrm{Ti}^{4+}$ (fig. 4) occurs already after a short exposure to oxygen just as found for the Fe implanted samples.

In combination with the ISS-results, we concluded also for the Ti-implanted samples that after oxidation a $\mathrm{TiO}_{2}$ overlayer and after a subsequent reduction a $\mathrm{TiO}_{2-x}$ overlayer was formed. The investigations of annealed samples, however, come to a different result as compared to iron implanted samples. The low-concentration sample showed no formation of $\mathrm{Ti}^{3+}$ after reduction. It seems, that $\mathrm{Ti}^{4+}$ cations dissolved in the zirconia lattice are only stable in their highest oxidation state under the applied conditions.

These results are in accordance with results obtained on bulk doped samples with different titania contents between 3.5 and $30 \mathrm{~mol} \%$ [19].

\subsection{Electronic surface properties}

With UPS it is possible in principle to obtain values of the work function $\Phi$, the ionization energy $I$, the difference between Fermi level $E_{\mathrm{F}}$ and the energy $E_{\mathrm{V}}$ of the valence band edge as well as the density of occupied states [17]. Therefore these methods are useful to detect additional electronic surface states in the band gap which may arise from cations like $\mathrm{Fe}^{2+}$ / $\mathrm{Fe}^{3+}$ or $\mathrm{Ti}^{3+} / \mathrm{Ti}^{4+}$ if they are in the magnitude of

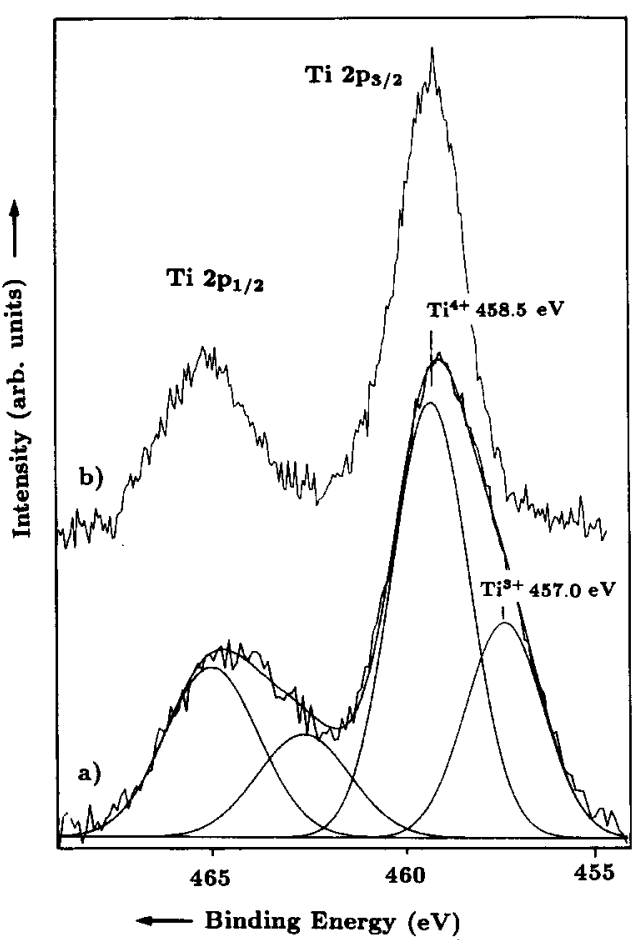

Fig. 4. XPS spectra for $\operatorname{Ti}\left(2 \mathrm{p}_{3 / 2,1 / 2}\right)$ : (a) after reduction at $800^{\circ} \mathrm{C}$ $P_{\mathrm{H}_{2}}=1 \mathrm{bar}, 15 \mathrm{~min}$; (b) after a subsequent exposure to a dose of $1000 \mathrm{~L}$ oxygen.

$0.1-1$ vol\%. EELS serves to determine the energy difference between valence band maximum and low lying unoccupied states as well as the value of the band gap $E_{\mathrm{g}}$.

\subsubsection{UPS}

Fig. 5a shows the UPS-spectra of a non implanted, polycrystalline YSZ-sample measured at $800^{\circ} \mathrm{C}$ together with an illustration of the definition and values for the work function (here: $4.7 \mathrm{eV}$ ) and $E_{\mathrm{F}}-E_{\mathrm{V}}$ (here: $3.3 \mathrm{eV}$ ). The Fermi level was stabilized by an $\mathrm{Fe} / \mathrm{FeO}$-back contact which fixes the oxygen activity at the contact with YSZ as described earlier [18]. Assuming that the electric field inside the YSZ-sample is zero due to the high ionic charge carrier concentration, no band-bending occurs and the position of the valence band maximum $E_{\mathrm{v}}$ measured at the front side of the sample is definitely related to the Fermi-level at the back side of the sample $[18,27,28]$.

The electronic structure of transition metal oxides 


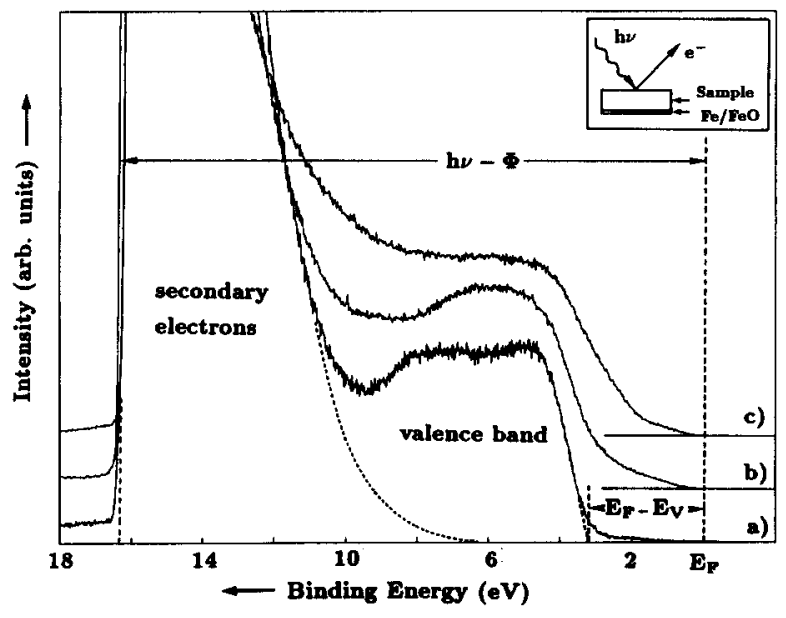

Fig. 5. Comparison of the UPS-spectra of the: (a) non-implanted YSZ; (b) low-concentration YSZ(Fe); (c) high-concentration YSZ(Fe). The valence band edge becomes shallower with increasing Fe content. An illustration of the definition of the work function $\Phi$ and the energy difference $E_{\mathrm{F}}-E_{\mathrm{v}}$ are given. The inlet shows the principle of the UPS experiment.

is characterized by the existence of an empty d-band and a valence band which arises mainly from oxygen $2 p$ states. The spectrum reveals a strong $\mathrm{O} 2 \mathrm{p}$ band in which two subbands at $4.9 \mathrm{eV}$ and $7.0 \mathrm{eV}$ can be distinguished. The principle feature of the valence band spectrum agrees with DV-Xa calculations of $\mathrm{ZrO}_{2}$ in the literature $[29,30]$, and with spectra from YSZ-single crystal [28]. In the bandgap above the valence band edge, a slight non-zero density of states could be observed which is clearly related to the high concentration of lattice defects.

In the same way as described in Sections 3.1 and 3.3, UPS-measurements were performed on "high"and "low-concentration"-samples after oxidation, reduction and oxygen-adsorption treatments. Fig. 5b shows the low-concentration, and $5 \mathrm{c}$ the high-concentration $\mathrm{YSZ}(\mathrm{Fe})$-sample. The valence band edge becomes more narrow with increasing iron concentration at the surface of YSZ and a slight density of states up to the Fermi level can be observed. Reduction of both, the high- and the low-concentration sample in hydrogen, leads to a distinct increase of the density of these states as shown in fig. $6 \mathrm{a}$ i.e. for the low-concentration-YSZ(Fe)-sample. In accordance with the XPS-results, we ascribe these additional electronic states to $\mathrm{Fe}^{2+}$ and metallic iron. A

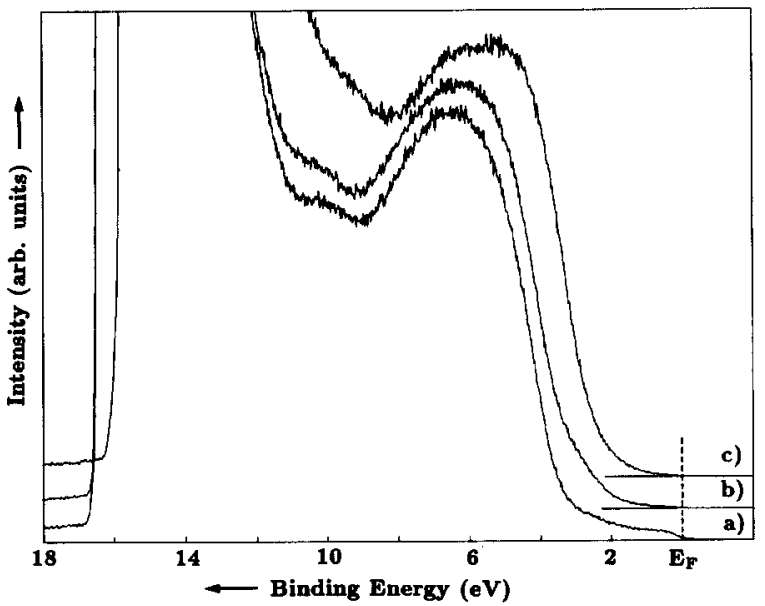

Fig. 6. UPS spectra of the annealed YSZ(Fe)-sample; recorded at $600^{\circ} \mathrm{C}$ : (a) after reduction at $800^{\circ} \mathrm{C} P_{\mathrm{H}_{2}}=1 \mathrm{bar}, 15 \mathrm{~min}$; (b) after absorption of $1000 \mathrm{~L}$ oxygen; (c) after oxidation at $800^{\circ} \mathrm{C}$, $P_{\mathrm{O}_{2}}=1$ bar, $15 \mathrm{~min}$.

subsequent exposure to $1000 \mathrm{~L}$ of oxygen is sufficient to reoxidize the sample as shown in fig. $6 \mathrm{~b}$. The spectrum $6 \mathrm{c}$ shows the oxidized sample $\left(1\right.$ bar $\mathrm{O}_{2}$, $800^{\circ} \mathrm{C}, 15 \mathrm{~min}$ ).

For the Ti-implanted sample, additional electronic states could only be observed after reduction of the as-implanted sample. The obtained spectrum

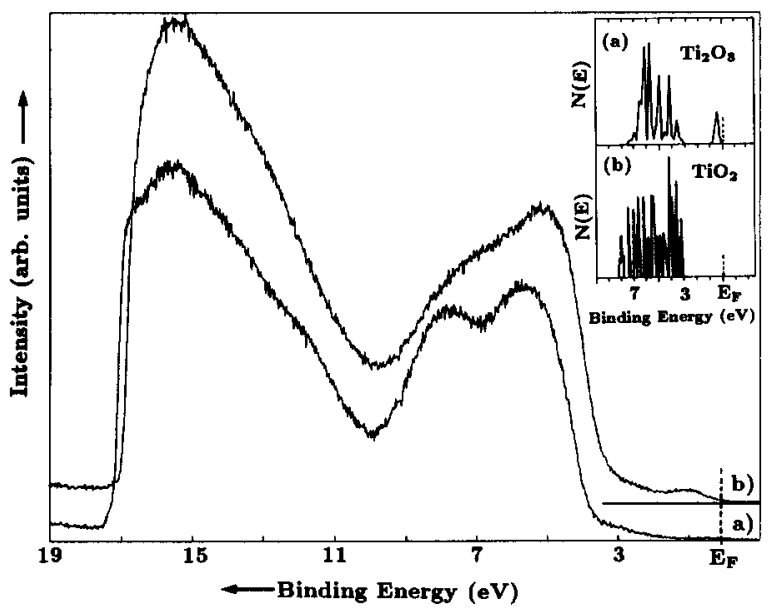

Fig. 7. UPS spectra of the YSZ(Ti) sample; recorded at RT: (a) after oxidation at $800^{\circ} \mathrm{C} P_{\mathrm{O}_{2}}=1$ bar, $15 \mathrm{~min}$; (b) after reduction at $800^{\circ} \mathrm{C} P_{\mathrm{H}_{2}}=1 \mathrm{bar}, 15 \mathrm{~min}$. The inlet shows the theoretical occupied one-electron density of states (DOS) for (a) bulk $\mathrm{Ti}_{2} \mathrm{O}_{3}$, and (b) bulk $\mathrm{TiO}_{2}[31]$. 
is depicted in fig. 7. A separate peak in the band gap at about $1 \mathrm{eV}$ below the Fermi level is clearly observed. This peak can be assigned to $\mathrm{Ti}^{3+}$ in accordance with XPS-results and theoretical calculations for $\mathrm{Ti}_{2} \mathrm{O}_{3}$ as mentioned in the insert of fig. 7 [31]. For a low-concentration sample, no indication for $\mathrm{Ti}^{3+}$ could be found.

\subsubsection{EELS}

The low energy loss features in the EELS spectrum

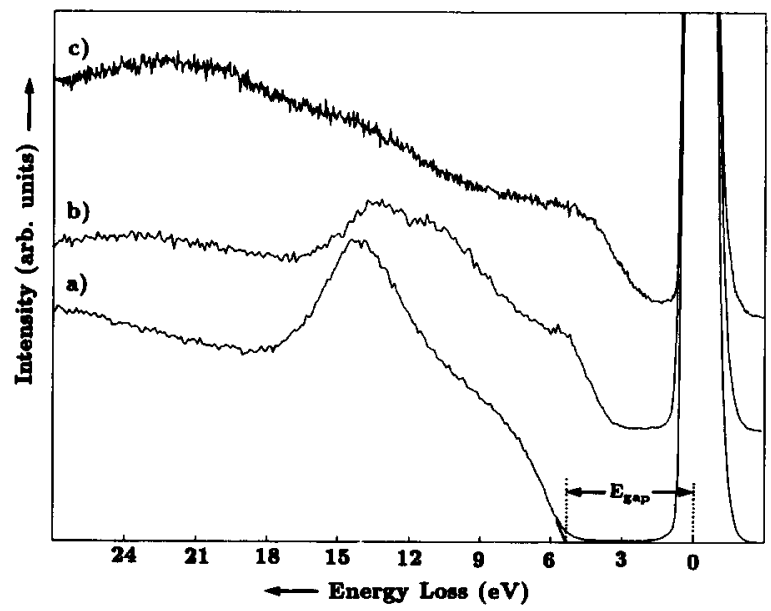

Fig. 8. Electron-energy-loss-spectra; $E_{\mathrm{p}}=300 \mathrm{eV}$ : (a) YSZ-single crystal; (b) YSZ(Ti)-sample; (c) YSZ(Fe)-sample. result from electronic transitions between valence band and conduction band. The band gap energy is derived from an extrapolation of the linear portion of the low energy edge in the loss spectrum to the baseline. This is illustrated in fig. 8 showing the EELS-spectra of (a) an YSZ-single crystal (b) the YSZ(Ti)-sample, and (c) the YSZ(Fe)-sample. The band gap of pure YSZ is derived as $5.2 \pm 0.2 \mathrm{eV}$ whereas a value of $3.6 \pm 0.2 \mathrm{eV}$ is obtained for the annealed Ti-implanted sample. Accordingly, dis-

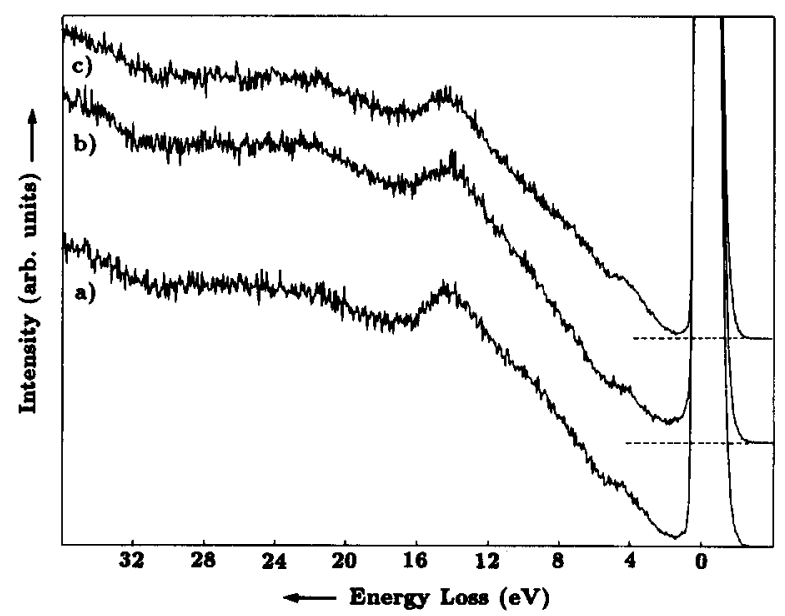

Fig. 9. EELS-spectra of the annealed YSZ(Fe)-sample; recorded at $600^{\circ} \mathrm{C}$ : (a) after reduction at $800^{\circ} \mathrm{C} P_{\mathrm{H}_{2}}=1$ bar, $15 \mathrm{~min}$; (b) after adsorption of $1000 \mathrm{~L}$ oxygen; (c) after oxidation at $800^{\circ} \mathrm{C}$, $P_{\mathrm{O}_{2}}=1$ bar, $15 \mathrm{~min}$.
a) YSZ
b) $\mathbf{Y S Z}(\mathbf{T i})$
c) $\mathbf{Y S Z}(\mathbf{F e})$
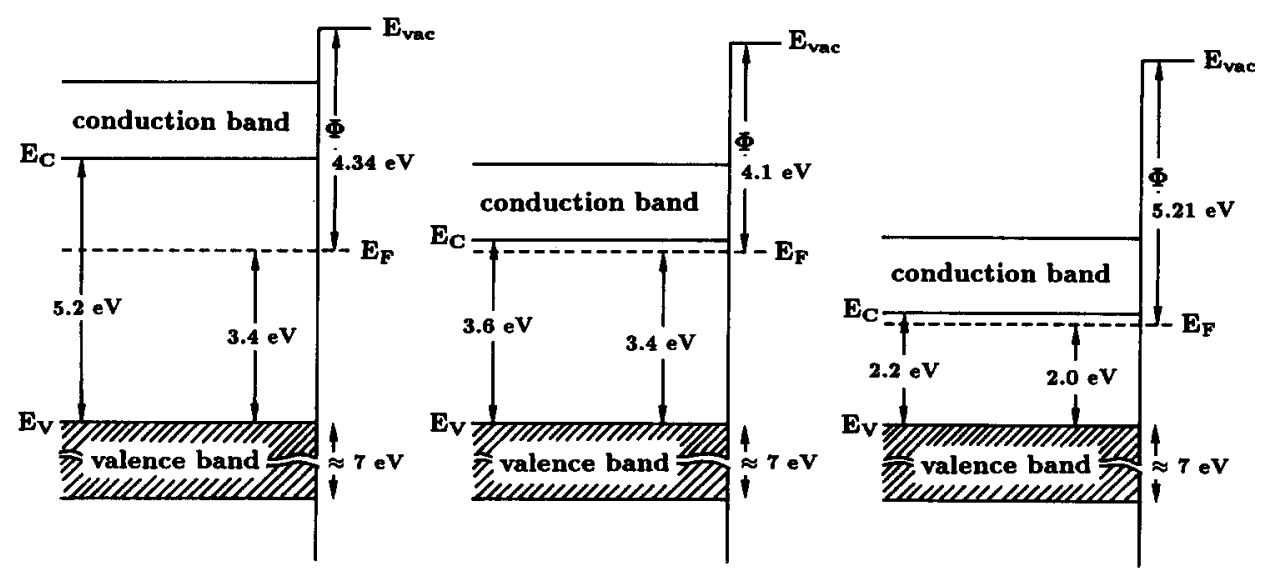

Fig. 10. Calculated band scheme from UPS-, XPS- and EELS-results: (a) $\left(\mathrm{ZrO}_{2}\right)_{0.87}\left(\mathrm{YO}_{1.5}\right)_{0.13}(\mathrm{YSZ})$; (b) annealed YSZ(Ti); (c) annealed $\mathrm{YSZ}(\mathrm{Fe})$. 
solving $\mathrm{TiO}_{2}$ in the YSZ-lattice results in a distinct decrease of the energy gap. This is in accordance with results obtained for YSZ doped with different contents of $\mathrm{TiO}_{2}$ [19]. For the annealed YSZ(Fe) the band gap was calculated to $2.2 \pm 0.2 \mathrm{eV}$. This value of the band gap is close to the optical bandgap of pure $\mathrm{Fe}_{2} \mathrm{O}_{3}(2 \mathrm{eV})$ as determined by Balberg et al. [33] and gives the $\mathrm{Fe}$ doped YSZ sample its orange color.

The reduction and oxidation cycles were studied with EELS, too. Fig. 9 shows EELS-spectra of an annealed YSZ(Fe)-sample after (a) oxidation, (b) reduction, and (c) after adsorption of $1000 \mathrm{~L}$ oxygen. For the reduced sample, additional energy losses in the band gap region are clearly observed which may be ascribed to metallic iron. After adsorption of $1000 \mathrm{~L} \mathrm{O}_{2}$, these states vanish in accordance with the UPS-results discussed in Section 3.4.1.

\subsubsection{Band scheme}

A combination of the results from XPS, UPS and EELS gives the band-scheme of the implanted samples. Fig. 10 shows the derived band schemes of (a) a non-implanted YSZ-sample, (b) the annealed Tiimplanted sample, and (c) the annealed Fe-implanted sample. It is evident, that implantation of $\mathrm{Ti}$ or Fe, leads to a distinct narrowing of the band gap. For the Ti-implanted sample, this is in accordance to measurements obtained on Ti-doped samples, as described previously [19]. For the iron-implanted sample, however, corresponding results with bulk doped YSZ are not available.

\section{Summary and conclusion}

We reported the influence of iron- and titaniumimplantation and subsequent treatments (oxidation, reduction) on the surface properties of polycrystalline yttria-stabilized zirconia. ISS-, RBS-, XPS-, UPSand EELS-measurements were performed to investigate the surface composition, the valence of the implanted ions as well as the electronic properties.

It can be concluded, that after implantation of $8 \times 10^{16}$ at $^{\mathrm{cm}^{-2}}$ iron or titanium and subsequent oxidation an overlayer is present consisting of $\mathrm{Fe}_{2} \mathrm{O}_{3}$ or $\mathrm{TiO}_{2}$, respectively. This overlayer can be reduced leading to the formation of $\mathrm{Fe}^{2+}, \mathrm{Fe}^{0}$ or $\mathrm{Ti}^{3+}$ and the generation of additional occupied states in the band gap. The implanted ions are rapidly oxidized to their highest oxidation state after an oxygen exposure of $1000 \mathrm{~L}$. Samples with a low surface concentration of the implanted ions, i.e. below the solubility level, behave different. Reduction of iron implanted samples leads again to the formation of $\mathrm{Fe}^{2+}$, whereas for titanium implanted samples no $\mathrm{Ti}^{3+}$ was formed after reduction. Iron doping of stabilized zirconia seems to be the better choice to achieve mixed conductivity by impurity ions.

\section{Acknowledgement}

The authors appreciate the cooperation with the Laboratorium voor Algemene Natuurkunde (LAN) of the University of Groningen. They are grateful to J.J. Smit for the ion implanter facilities. They thank Dr. D.O. Boerma for is supervision during the RBS measurements. They are indebted to Eng. A.H.J. van den Berg of the Centre for Material Science at the University of Twente for measuring the XPS depth profiles. The investigations were supported by the Netherlands Foundation for Chemical Research (SON) with financial aid from the Netherlands Organisation for Scientific Research (NWO) and from the Deutsche Forschungsgemeinschaft (DFG Go 301/15-1) of Germany.

\section{References}

[1 ] E.C. Subbarao and H.S. Maiti, in: Advances in Ceramics, Vol. 24B, Science and Technology of Zirconia III, eds. S. Somiya, N. Yamamoto and H. Yanagida (The Am. Ceram. Soc., Westerville, OH, USA, 1988 ) pp. 731-747.

[2] E.C. Subbarao and H.S. Mairi, in: Progress in Solid Electrolytes, eds. T.A. Wheat, A. Ahmed and A.K. Kuriakose (Energy Mines and Resources, Ottawa, Canada, 1983) pp. 281-312.

[3] E.J.L. Schouler, Solid State Ionics 9/10 (1983) 945.

[4] M.P. van Dijk, K.J. de Vries and A.J. Burggraaf, Solid State Ionics 21 (1986) 73.

[5] M.P. van Dijk, K.J. de Vries and A.J. Burggraaf, Solid State Ionics 21 (1986) 83.

[6] M.P. van Dijk, PhD Thesis (University of Twente, Enschede, The Netherlands, 1985).

[7] Y. Takasu, T. Sugino and Y. Matsuda, J. Appl. Electrochem. 14 (1984) 79. 
[8] A.J. Burggraaf, P.J. Gellings and D. Scholten, in: High Tech Ceramics, ed. P. Vincenzini (Elsevier, Amsterdam, 1987) pp. 779-794.

[9] B.A. van Hassel, PhD Thesis (University of Twente, Enschede, The Netherlands, 1990).

[10] D. Scholten, PhD Thesis (University of Twente, Enschede, The Netherlands, 1987).

[1 1 ] B.A. van Hassel and A.J. Burggraaf, Appl. Phys. A49 (1989) 33.

[12] B.A. van Hassel and A.J. Burggraaf, Solid State Ionics 57 (1992) 193.

[13] B. Poumellec, J.F. Marucco and F. Lagnel, Phys. Status Solidi (a) 89 (1985) 375.

[14] B.A. van Hassel, B.A. Boukamp and A.J. Burggraaf, Solid State Ionics 51 (1992) 161 .

[15] B.A. van Hassel and A.J. Burggraaf, Appl. Phys. A52 (1991) 410.

[16] K. Schindler, D. Schmeisser, U. Vohrer, H.-D. Wiemhöfer and W. Göpel, Sensors Actuators 17 (1989) 555.

[17] U. Vohrer, Thesis (Universität Tübingen, Germany, 1989).

[18] H.-D. Wiemhöfer, S. Harke and U. Vohrer, Solid State Ionics 40/41 (1990) 433.

[19] U. Vohrer, H.-D. Wiemhöfer, W. Göpel, F. Schilling and J. Arndt, Sensors Actuators B 4 (1991) 411.
[20] B.A. van Hassel and A.J. Burggraaf, Appl. Phys. A53 (1991) 155.

[21] W. Göpel, Sensors Actuators 16 (1989) 167.

[22] S.S. Liou and W.L. Worrell, Appl. Phys. A 49 (1989) 25.

[23] T. Choudhury, S.O. Saied, J.L. Sullivan and A.M. Abbot, J. Phys. D22 (1989) 1185.

[24] R.V. Wilhelm Jr. and D.S. Horwarth, Ceram. Bull. 58 (1979) 228.

[25] E. Paparazzo, Surface Interface Anal. 12 (1988) 115.

[26] B.M. Warnes, F.F. Aplan and G. Simkovich, Solid State Ionics 12 (1984) 271.

[27] H.-D. Wiemhöfer, U. Vohrer and W. Göpel, Mater. Sci. Forum 76 (1991) 265.

[28] H.-D. Wiemhöfer and U. Vohrer, Ber. Bunsenges. Physik. Chem. 96 (1992), to be published.

[29] M. Morinaga, H. Adachi and M. Tsukada, J. Phys. Chem. Solids 44 (1983) 301 .

[30] M. Morinaga, H. Adachi and M. Tsukada, Solid State Ionics $3 / 4$ (1981) 131.

[31] R.H. Tait and R.V. Kasowski, Phys. Rev. B20 (1979) 5178.

[32] A.J. Burggraaf, D. Scholten and B.A. van Hassel, Nucl. Instrum. Methods Phys. Res. B32 (1988) 32.

[33] I. Balberg and H.L. Pinck, J. Magn. Magn. Mater. 7 (1987) 12. 